\title{
PENGELOLAAN LIMBAH KIMIA DI LABORATORIUM KIMIA PMIPA FKIP UNRAM
}

\author{
Lalu Sulman, Jono Irawan
}

Staf Laboratorium Kimia PMIPA FKIP Universitas Mataram, Mataram, Indonaesia Email: sulmanlaluunram@gmail.com

\begin{abstract}
Abstrak: Limbah bahan kimia baik sisa praktikum maupun bahan kedaluarsa di Laboratorium Kimia PMIPA FKIP Universitas Mataram perlu dikaji secara mendalam, sehingga dapat ditemukan solusi bagaimana cara pengelolaan yang tepat. Untuk menemukan formula pengelolaan yang tepat diperlukan pengkajian tentang: identifikasi penyebab timbulnya limbah bahan kimia, perhitungan jumlah limbah, mekanisme pengolahan dan pembuangan ke lingkungan. Kuantitas limbah bahan kimia dan teknik pengelolaannya menjadi indikator seberapa baik tata kelola limbah. Tujuannya adalah untuk menemukan solusi dalam pengelolaan limbah bahan kimia, sehingga dapat dijadikan dasar/pedoman dalam upaya minimalisasi potensi limbah baik pada penanganan di gudang maupun pengurangan kuantitas limbah yang dihasilkan dari kegiatan praktikum di laboratorium PMIPA FKIP Universitas Mataram. Teknik dokumentasi yang digunakan dalam pengelolaan dapat diperoleh beberapa hal, yaitu: (1) limbah bahan kimia berasal dari sisa pembuatan larutan, sisa praktikum, hasil pencucian alat, dan bahan kedaluarsa. (2). Penurunan jumlah bahan kimia yang disimpan di gudang sebesar 18,5\% dari total persediaan, sedangkan jumlah bahan penyebab limbah B3 berkurang 29\%. (3) Diperlukan teknik pengolahan limbah bahan kimia tersebut sebelum dibuang ke lingkungan. (4) Rekomendasi usulan amandemen S.O.P Perencanaan, Penerimaan Bahan, Audit Gudang sehingga pencegahan pencemaran bahan kimia.
\end{abstract}

Kata kunci : Bahan kimia, Pengelolaan limbah, MSDS, Incompatibility, Standard Operating Procedure (S.O.P)

\begin{abstract}
Hazardous chemicals and materials practicum good rest expiry Chemistry Laboratory, University of Mataram PMIPA FKIP needs to be studied in depth, so as to find solutions on how to appropriate management. To find the right formula management studies are necessary regarding: the identification of the causes of chemical wastes, the calculation of the amount of waste, treatment and disposal mechanisms to the environment. The quantity of chemicals and waste management techniques to be an indicator of how well the governance of waste. The goal is to find a solution in the management of chemical waste, so it can be used as the basis / guidelines in an effort to minimize the potential for waste both in handling in the warehouse as well as a reduction in the quantity of waste generated from laboratory experiments PMIPA FKIP University of Mataram. Techniques used in the management of documentation may be obtained several ways, namely: (1) chemical wastes coming from the rest of the preparation of the solution, the rest of the lab, the results of the washing apparatus, and outdated materials. (2). Decrease the amount of chemicals stored in the warehouses of $18.5 \%$ of the total inventory, while the amount of material cause of the B3 waste is reduced by $29 \%$. (3) Required waste processing techniques such chemicals before being discharged into the environment. (4) Recommendations proposed amendments S.O.P Planning, Reception Materials, Audit Vault so that the prevention of chemical contamination.
\end{abstract}

Keywords: Chemicals, Waste management, MSDS, Incompatibility, Standard Operating Procedure (S.O.P)

\section{PENDAHULUAN}

Menurut pp no. 18 tahun 1999 pengertian limbah adalah sisa suatu usaha dan/atau kegiatan sedang limbah bahan berbahaya dan beracun disingkat menjadi limbah B3 adalah sisa suatu usha dan/atau kegiatan yang mengandung bahan berbahaya dan/atau beracun yang karena sifat dan/atau konsentrasinya dan/atau jumlahnya, baik secara langsung, maupun tidak langsung, dapat mencemarkan dan/atau merusakan linkungan hidup, dapat mencemarkan dan/atau merusakkan lingkungan hidup, dan/atau dapat membahayakan linkungan hidup, kesehatan, kelangsungan hidup manusia serta makhluk hidup lain [1].

Laboratorium kimia PMIPA FKIP Universitas Mataram adalah suatu unit kerja dibawah koordinasi laboratorim PMIPA FKIP Universitas Mataram dimana tanggungjawab utama adalah melayani praktikum mata kuliah. Kegiatan-kegiatan yang dilakukan di dalam laboratorium akan menghasilkan air buangan yang disebut air limbah, air limbah adalah air bersih yang telah terkontaminasi sehingga memiliki kualitas yang berbeda dari air yang 
belum terkontaminasi dalam parameter tertentu dan berpotensi besar dalam membahayakan kesehatan mahluk hidup. Ketentuan mengenai kualitas air buangan limbah di Indonesia telah diatur oleh Peraturan Menteri Negara lingkungan hidup No.3 tahun 2010 tentang baku mutu limbah cair, sehingga setiap laboratorium wajib mengatur kadar limbah buangannya dengan melakukan pengolahan dan tata kelola yang tepat sebelum membuang limbah cair.

Limbah yang dihasilkan laboratorium kimia sampai dengan saat ini belum pernah ditetapkan dengan teliti karena diasumsikan bahwa limbah tersebut tidak besar dan tidak berpotensi menjadi ancaman terhadap Keselamatan dan Kesehatan Kerja (K3). Jenis limbah hasil praktikum dan hasil analisis kimia terdiri dari : 1). Limbah padat, sisa hasil uji analisis, sisa hasil praktikum, bahan kimia kadaluarsa bentuk cair, tumpahan bahan kimia., sedangkan 2). Limbah cair : cuplikan contoh uji, bahan kimia kadaluarsa bentuk padat, bahan kimia rusak kemasan. Secara keseluruhan kuantitas timbulan limbah per bulan $\pm 3 \mathrm{Kg}$.

Selain dari kegiatan praktikum, limbah yang dihasilkan oleh laboratorium kimia PMIPA FKIP Universitas Mataram juga dapat berasal dari bahan-bahan yang sudah kadaluarsa dan bahan yang rusak kemasannya. Bahan kedaluarsa dan rusak kemasan diatur dalam PP No 101 Tahun 2014 pasal 31 ayat 2, bahan kimia kadaluarsa dan rusak kemasan merupakan salah satu jenis limbah. Limbah jenis inilah yang sering terjadi dan lebih berbahaya sehingga membutuhkan perhatian [2]. Jika limbah ini tidak dikelola dengan cepat, maka akan menyebabkan terbentuknya limbah-limbah yang lain. Limbah jenis ini terjadi karena tidak terkendalinya sistem pengelolaan bahan kimia sejak dari awal perencanaan, pembelian, sampai dengan pengaturan dan penempatannya di gudang penyimpanan. Oleh karena itu, perlu dilakukan pengelolaan limbah jenis ini dengan tepat.

Inventori dan penyimpanan bahan kimia di laboratorium merupakan kegiatan penting yang harus mendapat perhatian khusus oleh laboratorium kimia PMIPA FKIP Universitas Mataram karena sifat dan karakteristik dari bahan kimia tersebut sangat menentukan waktu dan lokasi tempat penyimpanan [3]. Saat ini jenis bahan kimia yang disimpan di gudang laboratorium kimia PMIPA FKIP Universitas Mataram meliputi 87 jenis bahan kimia cair dan 207 jenis bahan padat. Sistem tata kelola bahan kimia mulai dari perencanaan pembelian sampai penyimpanan dan pengelolaannya sangat berpengaruh terhadap kelancaran operasional laboratorium karena karakteristik dari masingmasing bahan kimia sangat siginfikan, sehingga dibutuhkan pengetahuan dan pengalaman khusus dalam bidang tatakelola dan penyimpanan bahan kimia di gudang. Penempatan penyimpanan bahan kimia dilakukan berdasarkan karaketristiknya, tidak bisa bercampur (incompatibility) dan potensi bahaya yang dimiliki menjadi dasar dari pengelom-pokannya di dalam ruang penyimpanan dengan tujuan agar tidak terjadi kontaminasi diantara bahan kimia tersebut sehingga tidak menimbulkan bahaya dan pencemaran didalam gudang penyimpanan.

Berdasarkan latar belakang diatas maka Tujuan penelitian ini adalah (1) untuk mengetahui inventori bahan kimia di laboratorium tahun 2015-2016, bahan kimia kadaluarsa, rusak kemasan, dan bahan kimia B3 mulai tahun 2015 sampai dengan tahun 2016. (2) untuk mengetahui kuantitas laju timbulan limbah di laboratorium kimia PMIPA FKIP Universitas mataram dalam kurun waktu 1 bulan. (3) untuk mengetahui sistem pengelolaan limbah dilaboratorium kimia PMIPA FKIP Universitas Mataram. Menurut Undang-Undang Republik Indonesia No. 32 tahun 2009, yang dimaksud dengan Bahan, Beracun, dan Berbahaya (B3) adalah zat, energi, dan/atau komponen lain karena sifat, konsentrasi, dan/atau jumlahnya, baik secara lanngsung maupun tidak langsung, dapat mencermarkan dan/atau merusak lingkungan hidup, dan /atau membahayakan lingkungan hidup, kesehatan serta kelagsungan hidup manusia dan makhluk lainnya [4].

Manfaat yang ingin dicapai melalui pengelolaan limbah kimia di laboratorium Kimia PMIPA FKIP Universitas mataram ini diharapkan dapat menemukan solusi dalam pengelolaan limbah kimia, sehingga dapat dijadikan pedoman dalam upaya minimalisasi potensi limbah baik pada penanganan di gudang maupun pengurangan kuantitas imbah yang dihasilkan dari kegiatan praktikum di laboratorium Kimia PMIPA FKIP Universitas Mataram.

\section{METODOLOGI PENELITIAN Jenis Penelitian}

Jenis penelitian ini adalah penelitian noneksperimen. Metode penelitian yang digunakan adalah metode descriptive survey, explanatory survey, dan metode klasifikasi. Metode penlitian ini bertujuan untuk memetakan suatu objek berdasarkan kriteria tertentu [5]. Unit analisis dalam penelitian ini adalah PLP laboratorium PMIPA FKIP Universitas Mataram. Penelitian ini termasuk pada katagori crossectional, yaitu informasi dari sebagian populasi (sampel responden) dikumpulkan langsung dari lokasi secara empirik dengan tujuan untuk mengetahui pendapat dari sebagian populasi terhadap objek yang diteliti yaitu pengelolaan limbah 
laboratorium kimia PMIPA FKIP Universitas Mataram. Penelitian ini menggunakan sumber data primer dan skunder. Data primer bersumber dari survei yang dilaksanakan melalui wawancara, observasi, dan kuesioner ke lapangan, sedangkan data skunder bersumber dari dokumentasi atau laporan-laporan yang berkaitan dengan objek yang diteliti dari pengelolaan limbah laboratorium untuk kemudian proses evaluasi terhadap prosedur yang sudah ada serta menghasilkan masukan untuk membuat rancangan prosedur baru yang lebih efektif dan efisien sebagai alternatif model pengelolaan limbah laboratorium.

\section{Ruang Lingkup Penelitian}

Ruang lingkup penelitian bertujuan untuk membatasi penelitian yaitu : (1) inventori bahan kimia di laboratorium tahun 2015-2016, bahan kimia kadaluarsa, rusak kemasan, dan bahan kimia B3 mulai tahun 2015 sampai dengan tahun 2016. (2) Kuantitas laju timbulan limbah di laboratorium kimia PMIPA FKIP Universitas mataram dalam kurun waktu 1 bulan. (3) system pengelolaan limbah dilaboratorium kimia PMIPA FKIP Universitas Mataram

Penelitian dilakukan di laboratorium kimia PMIPA FKIP Universitas Mataram yang berlokasi di Mataram, NTB.

\section{Pengambilan Data}

Data diperoleh melalui pencatatan jumlah bahan kimia yang dipakai dan bahan kimia yang kadaluarsa, bahan kimia rusak kemasan; pencatatan karakteristik limbah B3 terhadap bahan kimia kadaluarsa berdasarkan MSDS; pencatatan sumber dan kuantitas limbah padat, limbah cair yang dihasilkan kurun waktu 1 bulan; pencatatan kondisi awal dan setelah menerapkan sistem pengelolaan limbah kimia terhadap kuantitas timbulan limbah padat dan limbah cair di dilakukan di laboratorium kimia PMIPA FKIP Universitas Mataram dalam kurun waktu 1 bulan

\section{HASIL PENELITIAN DAN PEMBAHASAN Inventori Bahan Kimia di Laboratorium}

Hasil inventori bahan kimia yang disimpan di gudang laboratorium adalah selang waktu antara tahun 2015 - 2016 dapat dilihat pada tabel 1. Berdasarkan data pada tabel 1 inventori bahan kimia selama tahun 2015, bahan kimia tersebut dapat dibagi menjadi tiga kategori, yaitu bahan kimia sering dipakai (fast moving) dan bahan kimia tidak pernah dipakai (slow moving), dan bahan kadaluarsa. Bahan kimia sering dipakai (fast moving), artinya bahan tersebut dalam selang waktu 6 (enam) bulan terakhir aktif masuk dan keluar gudang. Tingkat kebutuhan dan tingkat pemenuhan bahan berlangsung seimbang sehingga tidak ada bahan kimia sisa ataupun tersimpan lama di gudang laboratorium. Bahan kimia tidak pernah dipakai (slow moving), artinya bahan tersebut dalam selang waktu 1 (satu) tahun tidak mengalami perubahan sehingga tidak dilakukan perencanaan tambahan pembelian. Bahan kimia ini masuk kedalam kategori timbulan limbah karena tidak dapat dipergunakan untuk analisis kimia. Penyimpanan sementara dilakukan dengan menempatkannya pada kompartemen rak terpisah dari bahan kimia belum kadaluarsa, namun masih didalam ruangan gudang bahan kimia. Rencana pembuangan bahan kadaluarsa belum dilaksanakan karena ada beberapa jenis dari bahan tersebut merupakan limbah bahan B3 yang pemusnahannya tidak dapat dilakukan di laboratorium kimia kimia PMIPA FKIP Universitas Mataram. Jumlah bahan kimia yang termasuk ke dalam ketiga kategori tersebut diberikan pada Tabel 2.

Perencanaan pembelian bahan kimia dilakukan berdasarkan ketiga kategori dalam Tabel 2. Pembelian bahan yang dilakukan sering tidak sesuai dengan usulan sehingga terjadi kekurangan dan kelebihan bahan. Kegiatan pencatatan antara kebutuhan dan pemenuhan bahan selama periode 1 (satu) tahun dilakukan dengan menghitung kekurangan atau kelebihan dari realisasi perencanaan. Bahan kimia yang tergolong slow moving mengalami kelebihan dari realisasi perencanaan, sedangkan bahan kimia yang tergolong fast moving secara keseluruhan memenuhi perencanaan pembelian bahan kimia tahun 2015.

Bahan-bahan yang sudah dibeli disimpan berdasarkan karakteristik dan sifat dari bahan tersebut dengan mempertimbangkan faktor ketidaksesuaian antara dua bahan kimia yang diletakkan berdekatan. Terdapat 13 kompartemen yang digunakan untuk menempatkan bahan kimia. Kompartemen A terdiri dari bahan korosif dan bahan tidak mudah terbakar, kompartemen B, bahan mudah terbakar dan tidak mudah terbakar, kompartemen C terdiri dari bahan tidak mudah terbakar dan bahan beracun, kompartemen D, bahan korosif, flamable dan non flammable, kompartemen $\mathrm{E}$ terdiri dari bahan toxic, kompartemen $\mathrm{F}$, bahan korosif, bahan oksidator, bahan flammable, kompartemen G, bahan korosif, bahan flamable dan bahan toxic, kompartemen $\mathrm{H}$, flamable, non flamable dan toxic, kompartemen I terdiri dari bahan korosif, flamable dan non flammable, kompartemen $\mathrm{J}$, bahan non flammable, kompartemen $\mathrm{K}$, bahan non flammable, kompartemen L, bahan korosif, oksidator, flamable dan non flammable, kompartemen $\mathrm{M}$, bahan korosif dan bahan flammable. 
Tabel 1. Bahan Kimia Laboratorium Kimia FKIP Universitas Mataram periode 2015 - 2016

\begin{tabular}{cc|c}
\hline Jenis bahan kimia & Jumlah & Kuantitas \\
\hline Cair & 87 & $304,2 \mathrm{~L}$ \\
Padat & 207 & $312,6 \mathrm{Kg}$ \\
Total & 294 & \\
\hline
\end{tabular}

Tabel 2. Jenis dan Jumlah Bahan Kimia yang Dipakai dan yang Kadaluarsa

\begin{tabular}{c|ccc}
\hline \multirow{2}{*}{ Jenis bahan kimia } & \multicolumn{3}{|c}{ Jumlah bahan kimia } \\
\cline { 2 - 4 } & Fast moving & Slow moving & Kada-luarsa \\
\hline Cair & 32 & 54 & 8 \\
Padat & 54 & 153 & 19 \\
\hline
\end{tabular}

\section{Bahan Kimia Kadaluarsa dan Rusak Kemasan}

Jumlah bahan kimia yang tersimpan di dalam gudang laboratorium berjumlah 293 jenis terdiri dari 86 jenis bahan kimia dalam bentuk cairan dan 207 jenis bahan kimia dalam bentuk padatan/serbuk.

Hasil penelitian menemukan 13 jenis bahan kimia dalam kondisi rusak kemasan dan 14 jenis bahan kimia sudah kadaluarsa atau tidak layak pakai sehingga didalam gudang penyimpanan bahan kimia terdapat limbah dan potensi pencemaran lingkungan yang sewaktuwaktu dapat menyulitkan pengelola laboratorium apabila tidak dikelola dengan sempurna. Hasil penelitian juga menemukan bahan kimia kadaluarsa ditempatkan didalam ruangan yang sama dan tidak dipisahkan. Hal ini bisa mengancam terjadinya bahaya dan pencemaran lingkungan gudang penyimpanan.

Jadi jumlah bahan kimia yang tidak dapat terpakai adalah 27 jenis. Apabila dibandingkan dengan jumlah total bahan kimia yang dimiliki, maka prosentase bahan kimia tidak terpakai menjadi $=27 / 293 \times 100 \%=9,2 \%$. Total ini berasal dari bahan kimia kadaluarsa dan rusak kemasan.

Kerusakan kemasan dari bahan kimia terjadi oleh karena kondisi suhu ruangan gudang penyimpanan bahan kimia yang mencapai rata-

rata $30{ }^{\circ} \mathrm{C}$. Suhu ini tercapai karena karena pengatur suhu ruangan (air conditioner) tidak berfungsi/rusak sehingga beberapa jenis dari kemasan tersebut bocor karena suhu panas dengan kelembaban $\pm 90 \%$ RH. Dalam waktu 3 (tiga) bulan cukup membuat kondisi dari kemasan bahan kimia yang tidak tahan panas menjadi rusak. Bahan kimia rusak kemasan tersimpan pada posisi semula, tidak ada upaya untuk melakukan pemisahan karena masih berharap bahwa bahan tersebut masih bisa dipakai.

Bahan kimia kadaluarsa terjadi karena selang waktu antara perencanaan pembelian sampai dengan kedatangan di gudang laboratorium membutuhkan waktu lama, sehingga pada saat bahan tiba masa kadaluarsa mendahuluinya. Bahan yang tergolong slow moving juga rentan mengalami kadaluarsa karena dianggap masih bisa dipakai. Usulan bahan kimia yang direncanakan dalam perencanaan pembelian belum tentu diterima, dan justru bahan yang tidak direncanakan (diperlukan) yang dibeli, sehingga bahan yang tidak direncanakan menjadi bahan slow moving dan seiring waktu akan menjadi bahan kadaluarsa. Selain itu, setelah diputuskan untuk membeli bahan tertentu, ternyata tidak dipergunakan oleh karena terjadi perubahan petunjuk praktikum.

\section{Perhitungan Timbulan Limbah}

Limbah B3 yang dihasilkan laboratorium kimia pada laboratorium kimia PMIPA FKIP Universitas Mataram setelah dilakukan identifikasi menurut sumber dan jenisnya, akan tetapi belum dibedakan sesuai dengan karakteristik limbah. Sebagaimana yang telah diatur dalam PP No,85 tahun 1999 adalah "limbah B3 dapat diidentifikasi menurut sumber dan atau uji karakteristik toksikologi" serta keputusan mentri lingkungan hidup No.18 tahun 2009 [6]

Hasil penelitian tentang identifikasi limbah B3 secara umum di laboratorium kimia telah sesuai dengan peraturan PP No. 85 tahun 1999 tentang pengelolaan limbah B3, serta keputusan mentri lingkungan hidup No.18 tahun 2009 tata tata cara perizinan pengelola limbah bahan berbahay dan beracun yang dipilih sesuai jenisnya telah sesuai dengan PP No.85 tahun 1999 tentang pengelolaan limbah B3.

Limbah cair yang dihasilkan sebelum penerapan sistem pengelolaan limbah kimia adalah sebesar $11,7 \mathrm{Kg}$ setiap bulan yang dibuang ke saluran pembuangan limbah. Setelah penerapan system pengelolaan limbah kimia pada laboratorium kimia PMIPA FKIP Universitas Mataram, jumlah limbah cair berkurang sebanyak $29 \%$, yaitu sebesar $8,32 \mathrm{Kg}$ setiap bulan, sedangkan limbah padat sebelum implementasi adalah sebesar $2 \mathrm{Kg}$ setiap bulan. Setelah penerapan sistem tata kelola limbah 
kimia pada laboratorium kimia PMIPA FKIP Universitas Mataram, total limbah padat berkurang sebanyak $24 \%$, yaitu sebesar $1,52 \mathrm{Kg}$. Dari jumlah limbah cair ditambah dengan limbah padat sebelum penerapan system pengelolaan limbah kimia pada laboratorium kimia PMIPA FKIP Universitas Mataram, sebesar 13,7 Kg per bulan di mana menurut jumlah ini termasuk ke dalam kategori Conditionally Exempt Small Waste Generator (x $<100 \mathrm{Kg})$. Setelah pengelolaan limbah kimia pada laboratorium kimia PMIPA FKIP Universitas Mataram, jumlahnya berubah menjadi $9,84 \mathrm{Kg}$ per bulan yang juga termasuk ke dalam kategori Conditionally Exempt Small Waste Generator (x $<100 \mathrm{Kg}$ ) [7] [8].

\section{Sistem Pengelolaan Limbah}

Laboratorium kimia PMIPA FKIP Universitas Mataram memiliki wewenang untuk mengelola limbah B3 dengan melakukan kegiatan penyimpanan sementara limbah B3 diarea B3. Kewajiban pengelola limbah B3 seperti terdapat pada PP No.85 tahun 1999 pasal 10 ayat 1 yaitu; penghasil limbah B3 dapat menyimpen limbah B3 yang dihasilkan paling lama 90 hari sebelum menyerahkan kepada pengumpul, pemanfaat, pengelola dan peminjam limbah B3". Dari pasal 10 ayat 2 yaitu: bila limbah B3 yang dihasilkan kurang dari 50 kilogram perhari, penghasil limbah B3 dapat menyimpan limbah B3 yang dihasilkan lebih dari 90 hari sebelum diserahkan kepada pemanfaat atau pengelola atau penerima atau penimbun limbah B3, dengan persetujuan kepala laboratorium atau intansi yang bertanggung jawab. izin penyimpanan sesuai dengan perizinan dan rekomendasi yang diberikan kantor kementrian dan lingkungan hidup dan sesuai dengan ketentuan yang berlaku yaitu peraturan pemerintah No.85 tahun 1999 tentang pengelola limbahB3 pasal 10 yaitu peyimpanan sementara limbah B3 kurang dari 90 hari dan penyimpanan sementara limbah B3 lebih dari 90 hari. Sehingga penyimpanan limbah laboratorium kimia telah memenuhi ketentuan PP No. 85 tahun 1999 tentang pengelola limbah. Laboratorium kimia PMIPA FKIP Universitas Mataran telah melakukan pengelolaan limbah B3 menurut PP No.85 tahun 1999 yaitu penyerahan limbah B3 kepada pemanfaat, serta kepada pengelola dan atau penimbun limbah B3 tidak mengurangi tanggung jawab penghasil limbah untuk mengolah limbah B3 yang dihasilkan sehingga penghasil limbah tetap bertanggung jawab dengan limbah B3 yang dihasilkan. Limbah laboratorium kimia yang perlu mendapat perhatian yaitu: 1). Bahan kimia kadaluarsa yang yang berjumlah 13 jenis diasumsikan sudah tidak layak pakai karena melewati masa kadaluarsa sehingga harus dipisahkan penyimpanannya dan pada akhirnya oleh pengelola laboratorium ditetapkan sebagai penyebab limbah. 2). Bahan kimia yang rusak kemasannya berjumlah 14 jenis yang disebabkan karena kondisi gudang yang mengalami kerusakan pengatur udara (air conditioner). 3). Bahan kimia berbahaya B3 yang dikelola laboratorium kimia berjumlah 134 jenis.

Bahan kimia kadaluarsa dan rusak kemasan yang dijumpai di gudang penyimpanan bahan laboratorium dikategorikan sebagai bahan berbahaya dan beracun (B3), oleh karena itu bahan tersebut juga masuk ke dalam kategori limbah bahan B3 yang memerlukan teknis serta pengetahuan khusus didalam pengelolaannya. Terdapat 20 (dua puluh) jenis bahan kimia kadaluarsa dan rusak kemasan dikategorikan sebagai limbah bahan B3. Menurut Peraturan Pemerintah (PP) No 18 tahun 1999 pasal 1 ayat 3 diwajibkan untuk dilakukan pengelolaan bahan tersebut melalui: reduksi, penyimpanan, pengumpulan, pengangkutan, pemanfaatan, pengolahan dan penimbunan harus dilakukan oleh pengelola laboratorium yang menghasilkannya.

\section{Tindakan Perbaikan}

Pemusnahan bahan kimia kadaluarsa yang merupakan bahan B3 tidak dapat dilakukan di laboratorium melalui cara insenerasi karena apabila bahan tersebut dibakar, maka dapat mengeluarkan gas-gas beracun. Bahan-bahan tersebut harus diserahkan kepada institusi atau lembaga pengolah limbah B3.

Pengelolaan limbah B3 dapat dilakukan mulai dari perencanaan pembelian, penyimpanan. Perbaikan pengelolaan dilakukan dengan memperbaiki prosedur pembelian, dan penyimpanan. Pada prosedur pembelian tidak memasukkan beberapa parameter kaji ulang yang berkaitan dengan upaya minimalisasi limbah. Pada prosedur semula perencanaan hanya menitik beratkan kepada jumlah, jenis dan waktu pengiriman bahan kimia yang sudah dibeli. Hasil penelitian ini memberikan masukan berupa usulan rancangan S.O.P prosedur perencanaan pembelian bahan kimia di laboratorium. Tujuannya adalah agar pada saat pengelola laboratorium menetapkan untuk membeli bahan kimia maka diharapkan juga semua parameter yang berhubungan dengan ancaman bahaya yang bisa ditimbulkan serta kerusakan lingkungan sudah dimasukkan sebagai salah satu pertimbangan. 
Tabel 3. Bahan kimia di gudang laboratorium

\begin{tabular}{c|c|c|c|c}
\hline Jenis bahan kimia & Sebelum & Rusak & Setelah & \% perbaikan \\
\hline Cairan & 86 & 8 & 78 & 9,3 \\
Powder & 207 & 19 & 188 & 9,2 \\
& 293 & & 266 & 18,5 \\
\hline
\end{tabular}

Prosedur penyimpanan dimulai dengan mendata bahan yang sudah diterima. Pendataan meliputi informasi spesifikasi, jumlah, karakteristik, dan tanggal bahan tersebut disimpan. Informasi tanggal diterimanya bahan tersebut dicatat pada label kemasan bahan kimia agar saat masa kadaluarsa terlampui, dapat dengan segera memisahkan tempat penyimpananya. Informasi mengenai usia simpan bahan kimia harus dimasukkan ke dalam inventori data base komputer sehingga selang waktu penyimpanan dari masing-masing bahan kimia dapat dengan mudah diketahui dan dapat ditelusuri apabila masa kadaluarsa terlampui. Ruang tempat penyimpanan harus sering diperiksa. Pemeriksaannya berupa bekerjanya alat sirkulasi udara, pengatur suhu ruangan, dan kelembaban gudang.

Prosedur tanggap darurat dibutuhkan untuk mengantisipasi apabila kondisi ruangan penyimpanan atau akomodasi lingkungan gudang bahan kimia berubah sehingga dapat dilakukan tindakan pengamanan terhadap bahan kimia yang tidak tahan terhadap suhu tinggi. Prosedur ini juga mampu untuk mengatasi tumpahan bahan kimia sehingga tidak terjadi polusi dan ancaman terhadap lingkungan. Apabila terjadi bahan kimia kadaluarsa kembali, maka dengan prosedur ini dipakai sebagai tindakan pengamanan terhadap bahan kimia lain yang masih baik dan tersimpan aman di gudang. Dengan adanya pemisahan antara bahan kadaluarsa, rusak kemasan dapat mengurangi $18,5 \%$ dari jumlah total bahan kimia berbahaya yang disimpan di laboratorium. Dari jumlah tersebut diatas dilakukan lagi pengelolaan inventori bahan kimia dengan memisahkan bahan kimia yang aktif dipakai (fast moving) dengan yang tidak pernah dipakai selang waktu 6 (enam) bulan yang diidentifikasi sebagai bahan kimia tidak pernah digunakan (slow moving) dengan maksud untuk mengetahui jumlah bahan yang tidak bergerak selang waktu 6 (enam) bulan yang akan dipergunakan sebagai informasi pada saat perencanaan bahan kimia dilakukan.

\section{KESIMPULAN}

Berdasarkan hasil penelitian dan pembahasan, maka kesimpulan yang dapat dibuat adalah 1) Implementasi manajemen pengelolaan bahan kimia dan limbah laboratorium mampu menghilangkan penyimpanan bahan kimia kadaluarsa dan rusak kemasan. Persediaan bahan kimia menurun sebesar 9,2\% dari kuantitas yang ada, disebabkan adanya pengurangan jumlah bahan yang tidak dipakai namun masih tercatat sebagai inventori. 2) Melalui manajemen pengelolaan limbah bahan kimia berupa pemisahan bahan kimia kadaluarsa dan rusak kemasan serta pengelolaannya mampu meminimalisasi potensi kontaminasi bahan kimia yang disimpan. 3) Jumlah timbulan limbah yang dibuang ke saluran pembuangan menurun dari $13,7 \mathrm{Kg} /$ bulan menjadi 9,84 Kg/bulan. 4). Pengelolaan limbah B3 pada laboratorium kimia mmeliputi: reduksi, pewadahan/pengumpulan, penyimpanan sementara, pengemasan, pelabelan dan symbol, pengangkutanintern, pemanfaatan, sedangkan untuk pengolahan dilakukan oleh pihak ke tiga sesuai dengan PP No. 85 tahun1999 tentang pengelolaan limbah bahan berbahaya beracun akan tetapi terdapat ketidak sesuaian dengan Kep.01/BAPEDA1/1999 yaitu mengenai pemberian symbol dan label yang jelas dalam kemasan limbah B3.

\section{REKOMENDASI}

Bahan kimia kadaluarsa yang tidak dapat dimusnahkan melalui insenerasi harus disimpan ditempat tersendiri dengan kondisi lingkungan yang dapat dikendalikan. S.O.P Perencanaan Pembelian Bahan Kimia, Penanganan dan Penyimpanan Bahan Kimia serta Audit Gudang perlu dioptimalkan melalui usulan rancangan perubahan S.O.P yang baru. Audit gudang harus dilaksanakan minimal 6 (enam) bulan dalam satu tahun. Hal ini untuk memperoleh akurasi data inventori sistem komputerisasi dengan kondisi gudang.perawatan, pengecekan, penyimpanan limbah B3 secara berkala, pemasangan label berdasarkan karakteristik dan pemasangan symbol yang sesuai karateristik masing_masing seperti label berbahaya,beracun.

\section{DAFTAR PUSTAKA}

[1] Riyanto. 2013. Limbah Bahan Berbahaya dan Beracun (Limbah B3). Yogyakarta: CV Budi Utama.

[2] Peraturan Pemerintah (PP) No.101 tahun 2014 tentang Pengelolaan Limbah Bahan Berbahaya Dan Beracun.

[3] Environment, Health \& Safety. 2010. Safe Storage of Hazardous Chemicals. Barkeley: university of California. 
[4] Putri, A.A., 2012, Desain Pengolahan Limbah Kimia laboratorium Dengan Prinsip reduce, Reuse, dan Recycle (Studi Kasus di FT IAIN Walisongo Semarang), Makalah Seminar Nasional Kimia dan Pendidikan Kimia IV UNS, Surakarta.

[5] Sumintono, B dan Widhiarso, W. 2015. Aplikasi Model Rasch Untuk Penelitian Ilmu-Ilmu Sosial. Trim Komunikata Publishing House.

[6] Peraturan Pemerintah (PP) No. 18 junto 85 tahun 1999.

[7] Environment Services Facility. 2011. Laboratory Pollution Prevention and Hazardous Waste Management Manual. Columbia: University of British Columbia.

[8] Conditionally Exempt Small Waste Quantity Generato Handbook For Hazardous Waste Handler. 2009. State of Connecticut Departement of Environmental Protection. 